\title{
The rise and fall of cancer mortality in the USA: why does pancreatic cancer not follow the trend?
}
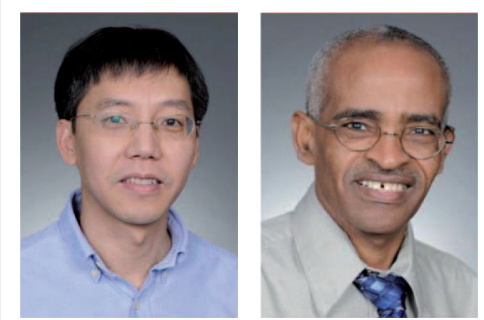

\author{
“...the 5-year relative survival rate for \\ pancreatic cancer is still only \\ approximately $6 \%$, and most patients \\ will die within 1 year of diagnosis."
}

Jiemin $\mathrm{Ma}^{\star 1}$ \& Ahmedin Jemal'

'Surveillance \& Health Services Research Program, American Cancer Society, 250 Williams Street, Atlanta, GA 30303, USA

*Author for correspondence: Tel. : +1 4049823654 m Fax: +1 4043276450 - jiemin.ma@cancer.org

After decades of increase, death rates from all cancers combined have been decreasing since the early 1990s among both men and women in the USA [1]. This trend largely reflects the evolution of death rates from the four major cancer sites, in other words, lung, colorectum, female breast and prostate. By contrast, the fourth-leading cause of cancer death in the USA - pancreatic cancer - has not been following the general cancer mortality trend over the years. Specifically, pancreatic cancer death rates have been increasing in both sexes since the early 2000s, after a three-decade decrease in men and a twodecade stable period in women [1]. Reasons for this trend discrepancy between all cancer and pancreatic cancer mortality can be found in all segments of the cancer continuum, from etiology and primary prevention through early detection and screening to treatment and survival.

\section{Etiology \& primary prevention}

Cigarette smoking has been a major driver of cancer mortality trends in the USA. Largely driven by lung cancer death rates, the rise and fall of all cancer mortality greatly mirrors the trends in smoking prevalence with a lag period of approximately 20-30 years, although early detection and/or treatment have played a major role in rate reduction for some specific cancer sites. Since its peak in the mid-1960s, adult smoking prevalence in the USA has continued to decrease over the last half century $[2,3]$.Correspondingly, all cancer mortality among men increased until 1990 and then decreased thereafter, coinciding with lung cancer mortality trends [1]. By contrast, among women, lung cancer death rates did not decrease until the early 2000s because of their later uptake of smoking epidemic $[1,4]$. Therefore, the decrease in all cancer mortality among women beginning in 1991 has been thought to be a combined result of a concurrent decrease in breast, colorectal and lung (younger than 65 years only) cancer death rates [5].

Pancreatic cancer is also a smoking-related disease; approximately $20 \%$ of pancreatic cancer deaths in the USA are attributable to cigarette smoking [6]. Unsurprisingly, it has been widely accepted that smoking was the main contributor to the increases in pancreatic cancer death rates from the 1930s to the early 1970s in men and from the 1930s to the mid-1980s in women, as well as the following decrease in men and leveling off in women until the early 2000s [5]. However, the reasons why the decrease and level off of pancreatic cancer death rates occurred 20 years earlier than that of lung cancer death rates remain largely unexplained. One possible reason is that smoking may serve as a late-stage carcinogen in pancreatic cancer occurrence. This is supported by a recent pooled analysis that found a quick reduction in pancreatic cancer risk after smoking cessation [7]. Alternatively, other risk factors may have modified the effects of smoking on pancreatic cancer trends over the years. Although this explanation remains to be tested, it is quite clear that recent changes in certain risk factors have offset the impacts of decreased smoking prevalence in the USA, as pancreatic cancer death rates have been increasing in both men and women since the early 2000s.

Of the possible contributors to the recent increases in pancreatic cancer deaths, obesity is clearly at the top of the list. Obesity has been reported to be associated with an approximate $20 \%$ increase in pancreatic cancer risk, compared with normal weight [8]. Over the past three decades, adult obesity prevalence in the USA has increased by approximately 3.5 -fold,

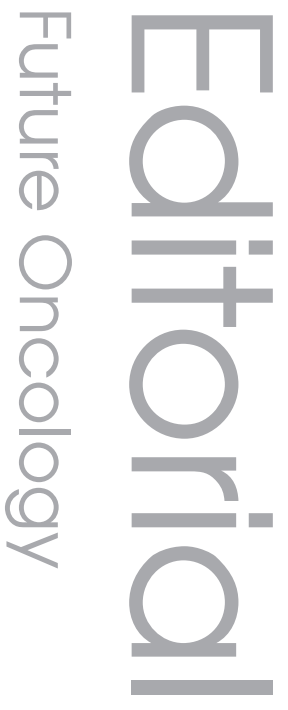

\section{Keywords}

- mortality $=$ pancreatic cancer $\approx$ screening $=$ smoking - survival

\section{Future $\because \%$ Medicine part of}


from $10 \%$ in $1976-1980$ to $36 \%$ in $2009-2010$ $[9,10]$. Owing to the possible long latency period between obesity and pancreatic cancer death, the consequences of fairly recent increases in obesity prevalence may have not fully manifested; the obesity epidemic is highly likely to lead to further increases in pancreatic cancer death rates. As the associations between pancreatic cancer and other lifestyle risk factors, such as physical inactivity and low intake of fruit and vegetables, are still unclear, the extent to which these factors have contributed to the recent increases in pancreatic death rates remains to be determined. It is also unclear whether recent advances in imaging techniques have artificially increased pancreatic cancer death rates in the USA, as reported in some European countries [11].

\section{Early detection \& screening}

Colorectal cancer screening was introduced in the early 1980s in the USA. By 2010, approximately $59 \%$ of USA adults aged $50-75$ years were up to date with their colorectal cancer screening according to US Preventive Services Task Force guidelines [12]. The widespread use of colorectal cancer screening has contributed substantially to the reductions in colorectal cancer mortality, as well as in colorectal cancer incidence through detection and removal of precancerous polyps [4]. By contrast, the benefits from mammography are concentrated on mortality reduction through detecting early-stage breast cancers. It has been estimated that mammography accounted for half of the reduction in breast cancer mortality in the USA [13]. In 2010, approximately $72 \%$ of women aged 50-74 years in the USA reported having had mammography during the past 2 years. Likewise, the use of the PSA test may have contributed to the substantial decreases in prostate cancer death rates since the early 1990s. However, there have been mixed results regarding the benefit of PSA testing in reducing prostate cancer mortality in recent clinical trials $[14,15]$. With regard to cervical cancer, the contribution of the Pap smear test to the reduction in incidence and mortality has been widely documented as a great achievement in cancer control and prevention [4].

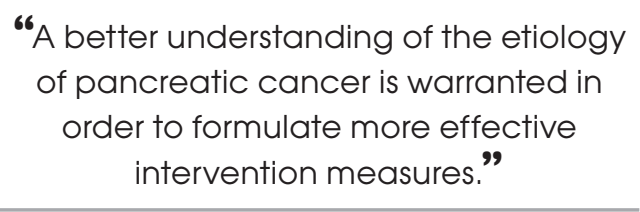

By contrast, so far there has been no such early detection method with sufficient sensitivity and specificity to serve as a tool for pancreatic cancer screening. In addition, the feasibility of pancreatic cancer screening among the general population is largely questionable, owing to the relatively low incidence rates. Thus, existing research programs on screening have been restricted to high-risk individuals, such as those with chronic pancreatitis, Peutz-Jeghers syndrome or familial atypical multiple mole melanoma syndrome [16]. Results from these studies showed that single use of endoscopic ultrasound or various combinations of imaging techniques are capable of detecting early pancreatic cancer or precancerous lesions among these high-risk populations [16]. However, it remains unclear whether screening by this method is effective in reducing pancreatic cancer mortality. Recent advances in understanding the molecular basis of pancreatic cancer may offer some promise for the discovery of new methods for the early detection of pancreatic cancer [17].

\section{Treatment \& survival}

Owing to the improvements in treatment of most cancers, the 5-year relative survival rate for all cancers combined has increased from 49 to $67 \%$ over the past 30 years [101]. By contrast, there have been no significant advances in developing effective treatment for pancreatic cancer. At present, the 5-year relative survival rate for pancreatic cancer is still only approximately $6 \%$, and most patients will die within 1 year of diagnosis [101]. One reason for this low survival rate is that most pancreatic cancers are diagnosed at a late stage, when the tumor has spread to surrounding tissues or distant organs. In the USA, only approximately $15-20 \%$ of pancreatic cancer cases are diagnosed early enough to be eligible for surgery - by far the only treatment that offers a chance of cure for pancreatic cancer patients. Even for patients with a tumor that has been surgically removed, the 5-year survival rate is only approximately $20-25 \%$. Treatment for patients with advanced disease still remains largely palliative. In recent years, researchers have discovered some promising molecular biomarkers for prognosis prediction; however, their prognostic and predictive values remain to be further validated [18].

\section{Conclusion}

In stark contrast to the decreasing rates for all cancers combined and other major cancer sites, pancreatic cancer death rates have been increasing since the early 2000s owing to the lack of progress in pancreatic cancer-specific primary 
prevention, early detection and treatment, as well as increases in risk factors such as obesity. In 2013, approximately 38,460 Americans will die of pancreatic cancer [19]. With the full manifestation of the consequences of obesity epidemic, this toll will continue to increase for many years if no urgent interventions are to take effect. Tobacco control and maintaining healthy body weight are the only two known intervention strategies. A better understanding of the etiology of pancreatic cancer is warranted in order to formulate more effective intervention measures. Researchers have recently found some promising biomarkers with potential applications in early detection and personalized treatment. To substantially improve pancreatic cancer treatment and survival, however, concerted efforts from basic-science researchers, pharmaceutical scientists and physicians are urgently needed.

\section{Financial \& competing interests disclosure \\ The authors have no relevant affliations or financial involvement with any organization or entity with a financial interest in or financial conflict with the sub- ject matter or materials discussed in the manuscript. This includes employment, consultancies, honoraria, stock ownership or options, expert testimony, grants or patents received or pending, or royalties. \\ No writing assistance was utilized in the production of this manuscript.}

\section{References}

1. Jemal A, Simard EP, Dorell C et al. Annual report to the nation on the status of cancer, 1975-2009, featuring the burden and trends in human papillomavirus (HPV)-associated cancers and HPV vaccination coverage levels. J. Natl. Cancer Inst. 105(3), 175-201 (2013).

2. Garrett BE, Dube SR, Trosclair A, Caraballo RS, Pechacek TF. Cigarette smoking - United States, 1965-2008. MMWR Surveill. Summ. 60(Suppl.), 109-113 (2011).

3. Giovino GA, Schooley MW, Zhu BP et al. Surveillance for selected tobacco-use behaviors - United States, 1900-1994. MMWR Surveill. Summ. 43(3), 1-43 (1994).

4. Jemal A, Ward E, Thun M. Declining death rates reflect progress against cancer. PLoS ONE 5(3), e9584 (2010).

5. Wingo PA, Cardinez CJ, Landis SH et al. Long-term trends in cancer mortality in the United States, 1930-1998. Cancer 97(12 Suppl.), 3133-3275 (2003).

6. Iodice $S$, Gandini S, Maisonneuve P, Lowenfels AB. Tobacco and the risk of pancreatic cancer: a review and meta-analysis. Langenbecks Arch. Surg. 393(4), 535-545 (2008).

7. Lynch SM, Vrieling A, Lubin JH et al. Cigarette smoking and pancreatic cancer: a pooled analysis from the pancreatic cancer cohort consortium. Am. J. Epidemiol. 170(4), 403-413 (2009).

8. Arslan AA, Helzlsouer KJ, Kooperberg C et al. Anthropometric measures, body mass index, and pancreatic cancer: a pooled analysis from the Pancreatic Cancer Cohort Consortium (PanScan). Arch. Intern. Med. 170(9), 791-802 (2010).

9. Flegal KM, Carroll MD, Kit BK, Ogden CL. Prevalence of obesity and trends in the distribution of body mass index among US adults, 1999-2010. JAMA 307(5), 491-497 (2012).

10. Flegal KM, Carroll MD, Kuczmarski RJ, Johnson CL. Overweight and obesity in the United States: prevalence and trends, 1960-1994. Int. J. Obes. Relat. Metab. Disord. 22(1), 39-47 (1998).

11. Bosetti C, Bertuccio P, Negri E, La Vecchia C, Zeegers MP, Boffetta P. Pancreatic cancer: overview of descriptive epidemiology. Mol. Carcinog. 51(1), 3-13 (2012).

12. CDC. Cancer screening - United States, 2010. MMWR Morb. Mortal. Wkly Rep. 61(3), 41-45 (2012).

13. Berry DA, Cronin KA, Plevritis SK et al. Effect of screening and adjuvant therapy on mortality from breast cancer. $N$. Engl. J. Med. 353(17), 1784-1792 (2005).
14. Schroder FH, Hugosson J, Roobol MJ et al. Screening and prostate-cancer mortality in a randomized European study. N. Engl. J. Med. 360(13), 1320-1328 (2009).

15. Andriole GL, Crawford ED, Grubb RL 3rd et al. Mortality results from a randomized prostate-cancer screening trial. $N$. Engl. J. Med. 360(13), 1310-1319 (2009).

16. Shin EJ, Canto MI. Pancreatic cancer screening. Gastroenterol. Clin. North Am. 41(1), 143-157 (2012).

17. Gemmel C, Eickhoff A, Helmstadter L, Riemann JF. Pancreatic cancer screening: state of the art. Expert Rev. Gastroenterol Hepatol. 3(1), 89-96 (2009).

18. Ansari D, Rosendahl A, Elebro J, Andersson R. Systematic review of immunohistochemical biomarkers to identify prognostic subgroups of patients with pancreatic cancer. Br. J. Surg. 98(8), 1041-1055 (2011).

19. Siegel R, Naishadham D, Jemal A. Cancer statistics, 2013. CA Cancer J. Clin. 63(1), 11-30 (2013).

\section{Website}

101. Howlader N, Noone AM, Krapcho M et al. SEER cancer statistics review, 1975-2009 (vintage 2009 populations). http://seer.cancer.gov/csr/1975_2009_ pops09/sections.html 